\title{
Spondylocostal Dysostosis with Sprengel Deformity: A Rare Association
}

\author{
Balaji $\mathrm{S}^{1}$, Indu $\mathrm{SV}^{2}$, Dinesh Kumar $\mathrm{N}^{3}$, Raghavendran $\mathrm{VD}^{4}$ \\ ${ }^{1}$ Dr Balaji S, Post Graduate student, ${ }^{2}$ Dr Indu S V, Post Graduate student, ${ }^{3}$ Dr Dinesh Kumar N, Assistant Professor, ${ }^{4}$ Dr \\ Raghavendran V D, Professor \& Head. All are affiliated with Department of Pediatrics, Sri ManakulaVinayagar Medical \\ College and Hospital (SMVMCH), Kalitheerthalkuppam, Puducherry, India
}

Address for correspondence: Dr Raghavendran V D, Email: raghavendr2011@yahoo.com

\begin{abstract}
Spondylocostal dysostosis (SCDO) refers to multiple segmentation defects of the vertebrae in combination with abnormalities of the ribs. Sprengel deformity is a congenital elevation of the scapula. Here, we would like to present a case of SCDO with associated Sprengel deformity, which has been reported only twice previously (to the best of our knowledge).
\end{abstract}

Key words: Vertebral Segmentation Defect, Rib Anomalies, Elevated Scapula, Jarcho Levin Syndrome

\section{Introduction}

Spondylocostaldysostosis (SCDO) radiographically means multiple segmentation defects of the vertebrae along with rib abnormalities. The patients often have a short trunk, a short neck and a mild, non progressive scoliosis. Sprengel deformity refers to congenital elevation of the scapula. It is found in rare, inherited, autosomal recessive disorders [1]. The association between SCDO (Jarcho Levin Syndrome) and Sprengel deformity have been reported twice previously. The first report was by Vijayan S et al in 2012 and the second report was by Mittal A et al in 2014 [2,3].

Here we would like to present a case of SCDO with associated Sprengel deformity that presented to our Paediatric Department.

\section{Case Report}

A 12 year old girl, the first born child of parents with non consanguineous marriage and normal ante natal, peri natal and post natal history, was brought to the outpatient department, with a deformed right sided shoulder joint. She was admitted for evaluation and management. According to the parents, even though the deformity was present since birth and caused cosmetic disfiguration, it did not affect the child's daily activities in any way and hence they had not sought any medical attention till date. But, as the child had complained of pain in the right shoulder of 1 week duration, she was brought to the hospital. There was no past history of recurrent respiratory infections. There was no similar history in the family. Her elder two siblings, a boy of 16 years and a girl of 14 years of age were developmentally and physically normal for their age.

On examination, she was noted to have a weight of 23.5 $\mathrm{kg}\left(<5^{\text {th }}\right.$ centile), a short stature (height of $132 \mathrm{~cm},<$ $5^{\text {th }}$ centile), mild scoliosis, asymmetrical chest wall and an elevated right scapula. There was limitation of abduction of right shoulder joint beyond 90 degrees. She was developmentally normal for her age. Systemic examination revealed no abnormal findings in her cardiac, respiratory, abdominal and nervous systems.

Computed Tomography (CT) of the spine showed segmentation fusion abnormalities of the C3-D3 vertebrae resulting in mild kyphoscoliosis along with dysraphic spine evident as a defect in the posterior arch (fig-1\&2). The right scapula was noted to be elevated and horizontally placed. The $1^{\text {st }} 3$ thoracic ribs on the left side showed bony fusion (fig-3). The superomedial angle of the right scapula was at the level of the C3 transverse process. This means that the Sprengel deformity was of a grade 3 severity, as per the Rigault's classification.(fig-4). 2D- Echocardiography was normal. Ultrasound abdomen was also normal. 


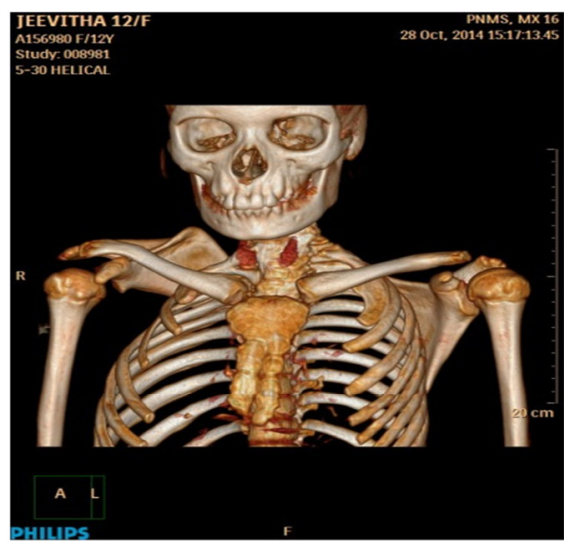

Fig-1 CT Anterior view showing segmentation fusion defect of the vertebrae.

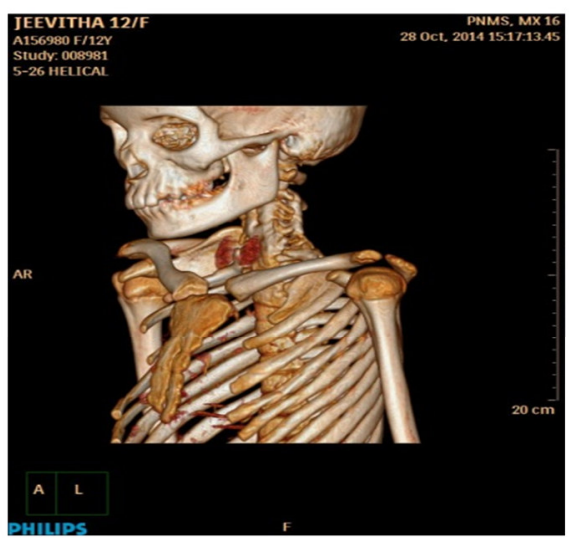

Fig-3 CT Anterolateral view showing first 3 thoracic ribs fusion on left side.

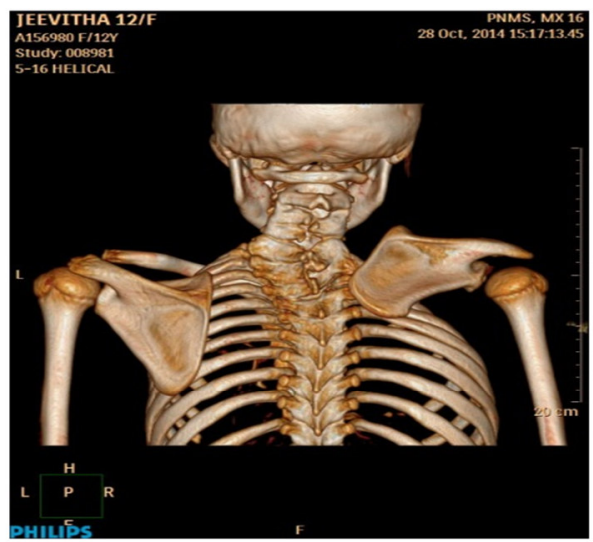

Fig-2 CT Posterior view showing segmentation fusion defect (C3D3 vertebrae).

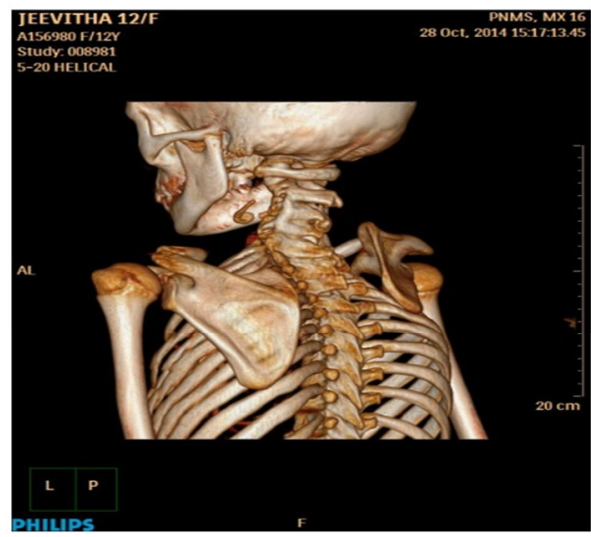

Fig-4 CT posterolateral view showing superomedial angle of right scapula at level of C3 transverse process.

Symptomatic treatment in the form of analgesics and physiotherapy was given to the child, to which she responded well. Orthopaedic consultation was taken. The child was advised to undergo Woodward procedure for the correction of her Sprengel deformity since parents did not give consent, surgery was not performed.

\section{Discussion}

In 1938, Jarcho and Levin described a rare developmental disorder; involving malformed ribs and vertebrae (Jarcho Levin Syndrome) [4]. But, the revised International Nomenclature of Constitutional Diseases of bone (1977) stated that, only the term, spondylocostaldysostosis (SCDO), be used for all patients with vertebral segmentation defects and rib abnormalities $[5]$.

SCDO is basically a radiographic description, which includes multiple segmentation defects of the vertebrae along with rib abnormalities. The rib abnormality can be fusion, malalignment or reduction in number of ribs. Clinically, it presents with a short trunk, a short neck and scoliosis which is mild and non-progressive in nature [1]. 

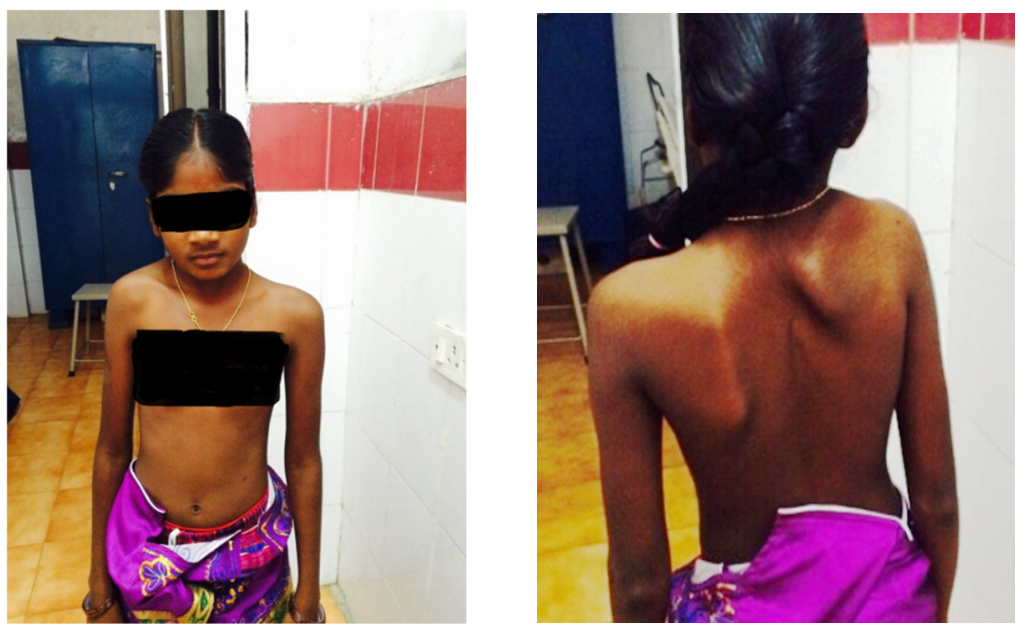

Case Report

Fig 5: The right scapula was noted to be elevated and horizontally placed

SCDO is inherited in an autosomal recessive manner. Till date four subtypes have been recognized based on the underlying mutant gene. These are, SCDO1 (DLL3associated SCDO), SCDO2 (MESP2-associated SCDO), SCDO3 (LFNG-associated SCDO) \& SCDO4 (HES7associated SCDO) [1].

Common associated abnormalities include urogenital/anal abnormalities, complex congenital heart diseases, limb and gait abnormalities and neural tube disorders $[6,7]$.

A close differential diagnosis is spondylothoracicdysostosis, which is an AR condition, characterized by crab/fan like deformities of the ribs which are posteriorly fused along with neural tube disorders. There will be severe thoracic restriction which leads to neonatal respiratory insufficiency and a very high mortality rate. Survivors require aggressive respiratory support and often go on to have recurrent chest infections in later life. This is thus different from SCDO, where there is a more benign course of illness and a normal life expectancy [8].

Embryologically, the scapula first appears around the $5^{\text {th }}$ week of gestation, in the mesenchyme and gradually migrates caudally. Around the end of the third month of gestational age, it reaches its final anatomical position. Sometimes, this caudal migration does not fully occur, and results in congenital elevation of the scapula. This is termed as Sprengel deformity [9].

According to Rigault, Sprengel deformity can be of 3 grades, based on the vertebral level at which the superomedial angle of the scapula lies. In Grade 1 deformity the superomedial angle is above T4 but lower than T2 vertebral process. In Grade 2, superomedial angle lies between $\mathrm{C} 5$ and T2 vertebrae whereas in Grade 3, the superomedial angle lies above the C5 vertebral process [9].

\section{Conclusion}

Clinical examination of the present case revealed stature $\left(<5^{\text {th }}\right.$ centile), mild scoliosis and an elevated right scapula with restriction of abduction beyond 90 degree. There is radiographic (CT) evidence of segmentation fusion abnormalities of the C3-D3 vertebrae, bony fusion of the first three thoracic ribs on the left side, elevation of right scapula with the superiomedial angle at the level of the C3 vertebrae and a dysraphic spine. Thus a diagnosis of Spondylocostaldysostosis with Grade 3 Sprengel deformity was arrived at.

\section{Funding: Nil}

Conflict of interest: Nil

Permission from IRB: Yes

\section{References}

1. Turnpenny PD, Young E, (International Consortium for Vertebral Anomalies and Scoliosis) I. SpondylocostalDysostosis, Autosomal Recessive. In: Pagon RA, Adam MP, Ardinger HH, Bird TD, Dolan CR, Fong C-T, et al., editors. GeneReviews(®) [Internet]. Seattle (WA): University of Washington, Seattle; 1993 [cited 2014 July 21]. Available from: http:/www.ncbi.nlm.nih.gov/books/NBK8828/

2. Mittal A, Sureka B, Mittal M, Aggarwal K. JarchoLevin syndrome with Sprengel's deformity: A rare entity. Medical Journal of Dr DY Patil University. 2014;7(3):408.

3. Vijayan S, Shah H. Spondylo-costal dysostosis with Sprengel's shoulder - Report of a new association with 
Jarcho-Levin syndrome. kjo. 2012 Jul 10;25(2):103 104.

4. Gangurde BA, Raut B, Mehta R, Thatte MR. The outcome of Jarcho-Levin syndrome treated with a functional latissimusdorsi flap - A series of three cases. Indian J Plast Surg. 2012;45(1):40-4.

5. International Nomenclature of Constitutional Diseases of Bone: Revision, May 1977. Am J Med Genet.1979;3:21-6.

6. Roberts AP, Conner AN, Tolmie JL, Connor JM. Spondylothoracic and spondylocostaldysostosis. Hereditary forms of spinal deformity. J Bone Joint Surg Br. 1988 Jan;70(1):123-6.
7. Srinivas BH, Puligopu AK, Sukhla D, Ranganath P. Rare association of spondylo costal dysostosis with split cord malformations type II: A case report and a brief review of literature. J PediatrNeurosci. 2014;9(2):142-4.

8. Cornier AS. SpondylothoracicDysostosis. In: Pagon RA, Adam MP, Ardinger HH, Bird TD, Dolan CR, Fong C-T, et al., editors. GeneReviews(®) [Internet]. Seattle (WA): University of Washington, Seattle; 1993 [cited 2014 Dec 24]. Available from: http://www.ncbi.nlm.nih.gov/books/NBK45316/

9. Kadavkolan AS, Bhatia DN, DasGupta B, Bhosale PB. Sprengel's deformity of the shoulder: Current perspectives in management. Int $\mathrm{J}$ Shoulder Surg. 2011;5(1):1-8.

\section{How to cite this article?}

Balaji S, Indu S V, DineshKumar N, Raghavendran V D. Spondylocostal Dysostosis with Sprengel Deformity: A Rare Association. Pediatr Rev: Int J Pediatr Res 2014;1(2):51-54. doi:10.17511/ijpr.2014.i02.02 